\title{
Recommendations on the first communication of genetic disease and malformation syndrome diagnosis: consensus issued by 6 Italian Scientific Societies and 4 Parents' Associations
}

\section{Gregorio Serra ( $\sim$ gregorio.serra@unipa.it)}

Department of Health Promotion, Mother and Child Care, Internal Medicine and Medical Specialties https://orcid.org/0000-0002-2918-9826

\section{Luigi Memo}

San Bortolo Hospital of Vicenza: Ospedale San Bortolo di Vicenza

\section{Alessandra Coscia}

Azienda Ospedaliero Universitaria Città della Salute e della Scienza di Torino: Azienda Ospedaliero Universitaria Citta della Salute e della Scienza di Torino

\section{Mario Giuffré}

University of Palermo: Universita degli Studi di Palermo

Ambra luculano

Ospedale Microcitemico: Azienda Ospedaliera Brotzu

\section{Mariano Lanna}

Vittore Buzzi Children's Hospital: Ospedale dei Bambini Vittore Buzzi

Diletta Valentini

Bambino Gesu Pediatric Hospital: Ospedale Pediatrico Bambino Gesu

\section{Anna Contardi}

Italian Association of Down People

\section{Sauro Filippeschi}

Italian National Association of Volunteers Cornelia de Lange

\section{Tiziana Frusca}

University of Parma: Universita degli Studi di Parma

\section{Fabio Mosca}

University of Milan: Universita degli Studi di Milano

\section{Luca A. Ramenghi}

Giannina Gaslini Children's Hospital: Istituto Giannina Gaslini

\section{Corrado Romano}

OASI Maria SS IRCCS for Mental Retardation and Cerebral Involution: Associazione OASI Maria SS

\section{Annalisa Scopinaro}

Italian Federation of Rare Diseases 


\section{Alberto Villani}

Bambino Gesu Pediatric Hospital: Ospedale Pediatrico Bambino Gesu

\section{Giuseppe Zampino}

Catholic University of the Sacred Heart: Universita Cattolica del Sacro Cuore

\section{Giovanni Corsello}

University of Palermo: Universita degli Studi di Palermo

\section{Research}

Keywords: Genetic disease, Malformation syndrome, Communication of diagnosis, Consensus, Recommendations

Posted Date: February 10th, 2021

DOl: https://doi.org/10.21203/rs.3.rs-198848/v1

License: (c) (i) This work is licensed under a Creative Commons Attribution 4.0 International License. Read Full License

Version of Record: A version of this preprint was published at Italian Journal of Pediatrics on April 19th, 2021. See the published version at https://doi.org/10.1186/s13052-021-01044-1. 


\section{Abstract}

\section{Background}

Genetic diseases are chronic conditions with relevant impact on the lives of patients and their families. In USA and Europe it is estimated a prevalence of 60 million affected subjects, $75 \%$ of whom are in developmental age. A significant number of newborns are admitted in the Neonatal Intensive Care Units (NICU) for reasons different than prematurity, although the prevalence of those with genetic diseases is unknown. It is, then, common for the neonatologist to start a diagnostic process on suspicion of a genetic disease or malformation syndrome, or to make and communicate these diagnoses. Many surveys showed that the degree of parental satisfaction with the methods of communication of diagnosis is low. Poor communication may have short and long-term negative effects on health and psychological and social development of the child and his family. We draw up recommendations on this issue, shared by 6 Italian Scientific Societies and 4 Parents' Associations, aimed at making the neonatologist's task easier at the difficult time of communication to parents of a genetic disease/malformation syndrome diagnosis for their child.

\section{Methods}

We used the method of the consensus paper. A multidisciplinary panel of experts was first established, based on the clinical and scientific sharing of the thematic area of present recommendations. They were suggested by the Boards of the six Scientific Societies that joined the initiative: Italian Societies of Pediatrics, Neonatology, Human Genetics, Perinatal Medicine, Obstetric and Gynecological Ultrasound and Biophysical Methodologies, and Pediatric Genetic Diseases and Congenital Disabilities. To obtain a deeper and global vision of the communication process, and to reach a better clinical management of patients and their families, representatives of four Parents' Associations were also recruited: Italian Association of Down People, Cornelia de Lange National Volunteer Association, Italian Federation of Rare Diseases, and Williams Syndrome People Association. They worked from September 2019 to November 2020 to achieve a consensus on the recommendations for the communication of a new diagnosis of genetic disease.

\section{Results}

The consensus of experts drafted a final document defining the recommendations, for the neonatologist and/or the pediatrician working in a fist level birthing center, on the first communication of genetic disease or malformation syndrome diagnosis. Although there is no universal communication technique to make the informative process effective, we tried to identify a few relevant strategic principles that the neonatologist/pediatrician may use in the relationship with the family. We also summarized basic principles and significant aspects relating to the modalities of interaction with families in a table, in order to create an easy tool for the neonatologist to be applied in the daily care practice. We finally obtained an intersociety document, now published on the websites of the Scientific Societies involved. 


\section{Conclusions}

The neonatologist/pediatrician is often the first to observe complex syndromic pictures, not always identified in the prenatal period. It is necessary for him to know the aspects of genetic diseases related to communication and bioethics, as well as the biological and clinical ones, which together outline the cornerstones of the multidisciplinary care of these patients. This consensus provide practical recommendations on how to make the first communication of a genetic disease /malformation syndrome diagnosis. The proposed goal is to make easier the informative process, and to implement the best practices in the relationship with the family. A better doctor-patient/family interaction may improve health outcomes of the child and his family, as well as reduce legal disputes with parents and the phenomenon of defensive medicine.

\section{Background}

Genetic diseases are chronic conditions with relevant impact on the lives of patients and their families. In USA and Europe, it is estimated a prevalence of 60 million affected subjects (with an incidence of major malformations of $3 \%$ on the total of newborns), $75 \%$ of whom are in developmental age (in about a quarter of cases the diagnosis of such pathologies is made and communicated after the pediatric age) [1, 2]. A significant number of newborns are admitted in the Neonatal Intensive Care Units (NICU) for reasons different than prematurity, although the prevalence of those with genetic diseases is unknown [1]. It is common, therefore, for the neonatologist to start a diagnostic process on the suspicion of a genetic disease or malformation syndrome, or to make and communicate these diagnoses. He is often the first to inform parents, and communication is even more difficult when such news is unexpected. The communication of diagnosis is part of the daily work of the neonatologist and pediatrician and must be considered a medical act in all respects, like any other diagnostic or therapeutic procedure. For the neonatologist and the pediatrician of a birthing center, informing parents that their baby is affected by a malformation syndrome is one of the most delicate and difficult experiences. The methods of communication of diagnosis and the content of the information provided are decisive for parents to control their emotions, ease the painful effect of the news and find resources to face the future. Many surveys assessed the degree of parental satisfaction with the methods of communication of diagnosis [3, 4]. They showed that dissatisfaction is avoidable, and that it is not linked to the condition object of the communication, but to the modalities in which it is demonstrated and explained [3]. Moreover, poor communication may cause distrust and aversion towards doctors, and prevent good cooperation between family and health care professionals. It has a long-term negative effect both on the ability to accept the diagnosis and to adapt to the new situation, and on the developing relationships between parents and children. Health and psychological and social development of the child may be, then, adversely affected for a long time. In the international literature specific guidelines on this topic are few and not recent. We draw up recommendations on this issue, shared by 6 Italian Scientific Societies and 4 Parents' Associations, aimed at making the neonatologist's task easier, at the time of communication to parents of a genetic disease/malformation syndrome diagnosis for their child. The goal is also to 
reassure families on the most suitable care pathway, avoid raising inappropriate expectations and, at the same time, enhance existing resources.

\section{Methods}

We used the method of the consensus paper $[5,6]$. A multidisciplinary panel of experts was first established, based on the clinical and scientific sharing of the thematic area which is object of the recommendations.

Doctors with specific expertise and experience, acquired in communicating a genetic disease diagnosis, were identified. They were suggested by the Boards of the six Scientific Societies which joined the initiative: Italian Societies of Pediatrics, Neonatology, Human Genetics, Perinatal Medicine, Obstetric and Gynecological Ultrasound and Biophysical Methodologies, and Pediatric Genetic Diseases and Congenital Disabilities. To obtain a deeper and global vision of the communication process, and to reach a better clinical management of patients and their families, representatives of four Parents' Associations were also recruited: Italian Association of Down People, Cornelia de Lange National Volunteer Association, Italian Federation of Rare Diseases, and Williams Syndrome People Association. They worked from September 2019 to November 2020 to achieve a consensus on the recommendations for the communication of a new diagnosis of genetic disease.

Initially, a systematically revision of the literature was made, inserting the terms "communication", "diagnosis", "genetic/genomic disease", "congenital malformation", "newborn" in the PubMed search engine. The papers published from 2005 to date were analyzed, also relating to thematic areas different than clinical genetics, such as clinical psychology and bioethics, thus allowing an integration between the aspects of genetic diseases related to communication and bioethics and the biological and clinical ones, also considering the new techniques of genomic diagnosis. A small nucleus of experts redacted the first report, summarizing all available scientific information. It was then submitted to the attention of a multidisciplinary jury, composed by representatives of the Scientific Societies and by the Presidents/Coordinators of the Parents' Associations involved. The document thus produced was subsequently revised by an extended team of experts, made also by the Presidents and Study Groups Coordinators of the participating Scientific Societies.

\section{Results}

The consensus of experts drafted a final document defining the recommendations, for the neonatologist or the pediatrician working in a fist level birthing center, relating to the first communication of a genetic disease or malformation syndrome diagnosis. Although there is no universal communication technique to make the informative process effective, we tried to identify a few relevant strategic principles which the neonatologist/pediatrician may use in the relationship with the family. We also summarized basic principles and the most relevant aspects on the modalities of interaction with families in a table, to create 
an easy tool for health care professionals to be applied in the daily care practice. We finally obtained an intersociety document, now published on the websites of the Scientific Societies involved.

\section{Discussion}

The communication of a diagnosis of a disease with poor or disabling outcome, in which an effective therapeutic and support plan may not be proposed, is a negative event from an emotional and relational point of view. Good communication is recognized as a pivotal feature for healthcare professionals, and needed for the quality of care they provide [7]. This ability is continuously subjected to evaluation by patients, who always consider it a priority among doctor's skills [8]. Moreover, it is documented that physicians perceive themselves more effective in communicating with patients when their clinical suspicion is confirmed by genetic (cytogenetic and/or molecular) investigations. By converse, families report that communicative effectiveness does not depend on the diagnostic definition. The importance attributed by doctors to diagnosis may reflect their well-known tendency to give value to clinical tests and to diagnostic or therapeutic procedures, while many patients give more weight to the intrinsic importance of the communication process (defined as personal utility) [8]. However, in Italy there is to date no specific training course for the medical profession, during the degree course, aimed at acquiring communication skills, nor subsequently for the neonatologist, during the Specialization School in Pediatrics. Performing simulations of communication scenarios, within the specific clinical activities of each care setting, may be useful for improving staff skills [9].

Improving the doctor-patient/family relationship may have a favorable effect on health outcomes of children and their parents, as well as reduce the phenomenon of defensive medicine and the medico-legal disputes. To implement optimal doctor-patient relationships, the principles of family-centered-care (such as, for example, collaborating with families and respecting their diversities, sharing information and providing individualized care) must be part of post-graduate training courses, policies and operational protocols of hospitals, and behaviors of neonatology and pediatric departments staff [10].

Relationships between team members and parental couple have a major impact in supporting parents' role, especially if continuity and uniformity of medical and nursing care is guaranteed. Many behaviors of health professionals negatively considered by parents widely reflect difficulties in communication or interpersonal skills, such as a reduced amount of time dedicated to information, or a modality without sensitivity, or also an attitude excessively oriented to clinical aspects. Simple actions, such as increasing attention to the time intended for news transmission, simplifying and adapting language to the interlocutor's profile, recognizing the positive aspects of the child, and especially the attitudes which offer support (practical and emotional) to parents' role, may be decisive. It is essential to understand families' point of view, because it allows to interpret their needs [11], and therefore to identify possible solutions to the most pressing problems, sometimes apparently far from doctors' competences.

In the case of the first communication of a genetic disease diagnosis, the neonatologist/pediatrician has the aim of creating the relationship between health professionals and family. Thus, he lays the 
foundations to guide parents towards the clinical goal and, through a circular path, he supports and increases trust in their child, giving further strength to the care process. At the same time, he provides all the technical information on the updated clinical and scientific data of the disease which is object of the communication.

In the case of a malformative picture which is evident at birth, communication is particularly challenging, especially if prenatal diagnosis is lacking. In these circumstances, the neonatologist must simultaneously fulfill, in an urgent situation, therapeutic management (stabilizing the adaptation to extrauterine life and preventing any complications), diagnostic procedures (aimed at identifying the cause of the clinical picture), and communication with the parental couple. Parents, indeed, in a context of extreme intensity and vulnerability, must be adequately and timely informed, and involved in the care process. The neonatologist is faced with pressing questions, such as: "what and why did it happen? who is responsible for it? may other problems arise? may they be cured? how will he/she be when he/she grows up? ... ", and many others will emerge in a short time. Communication with parents in the first hours after birth is then difficult and often decisive, and requires immediacy, sensitivity, experience and adequate skills [12]. The information transmitted, the verbal and non-verbal language used, the place and context in which this occurs, will have a profound impact on the family for many years [13]. Poor communication has, in fact, a long-term negative effect both on the ability to accept diagnosis and to adapt to the new situation, and on the developing relationships between parents and children. Therefore, health and psychological development of the child may be adversely affected for a long time.

There is no communication technique which may be considered effective in all circumstances. However, we may indicate 5 strategic principles:

1. Flexibility. The operator must adapt himself to the interlocutor's cultural and social level, removing commonplaces and prejudices. The higher the level of preconception is, the greater the degree of stereotypy of the communicative moves increases. This is followed by lowering of the therapeutic efficacy, and removal of parents.

2. Attitude of listening towards family.

3. Parsimony. Clear messages, formulated with suggestive style and sparingly delivered, are easy to understand, generally effective, and get the most for the least. They must not be overly specific, full of technicalities and scientific references. Rather, it can be useful to use anecdotes, metaphors or examples, which lead to greater involvement of parents allowing them to follow suggestions and prescriptions with commitment and trust.

4. Usage/empathy. It consists of the use of every element that comes from parents (language, attitude, arguments, etc. ...) for the primary aim of communication, that is the creation of the relationship between health care professionals and family. We must avoid to openly contest the parental couple: every "clash" may be a danger for the relationship, and favor mechanisms of closure and distrust.

5. Restructuring. It means to insert the definition of a problem within other systems of meaning. It implies helping family to identify different points of view on aspects of their life experienced, until that moment, as particularly critical and painful. This is useful and functional, also in order to guide 
parents towards what "they can do" within the diagnostic-therapeutic and/or support plan proposed by the health care professional.

Communication is strategic if it respects these 5 principles. To formulate specific interventions it is essential to know the interlocutor, and to be able to recognize his multiple signals. To grasp and understand all the possible traces that the family may provide in the relationship, it is necessary to give all the time needed to communication. The "psychic time" of parents, which is requested for accepting a child unlike from what they imagined until that moment, is often different than that of the medical intervention. Recognizing this time and being generous with one's own have, then, a therapeutic as well as an ethical value.

It may be useful to resort to some gimmicks to improve communication effectiveness. It may be advantageous, for example, while still maintaining objectivity, to provide first the positive aspects of a news, and then introduce the negative ones. Reversing this order decreases the positive part of the information, because the negative news, which is perceived as the most relevant, if presented first inhibits the perception of the positive one. To increase communication effectiveness, speeches must be directly reported to the interlocutor, avoiding impersonal expressions. These phrases do not recognize to families the specificity of their experience and the particularity of the interaction in which they are involved. A personalized communication takes into account the subject, and is full of references to his experience. It is preferable to use the first plural person (we), instead of the first and second singular one. In this way, it is transmitted the message of being involved in the relationship, and a greater willingness to perform specific behaviors may be obtained. A continuous and direct eye contact reflects true interest, and it guarantees active listening [14]. In Table 1 are summarized the indications for the neonatologists/pediatricians on the first communication of genetic disease/malformation syndrome diagnosis. It may be a useful and practical tool to make easier the informative process with the parents of these patients, as well as to implement the best practices in the relationship with families.

Table 1. Indications for the neonatologist and the pediatrician to make easier the communication of a genetic disease and/or malformation syndrome diagnosis, and to implement the best practices in the relationship with families $[15,16]$.

The pediatrician-parents relationship is a communicative situation in which the goal is common and shared. The strategic mandate of the pediatrician consists of 1 ) leading the relationship; 2) accompanying parents towards the clinical goal; 3 ) keeping always high motivation and trust; 4 ) ensuring good levels of compliance and managing any unexpected events.

Sometimes fulfilling this task is for the pediatrician a simple, spontaneous and immediate activity. In fact, with many parents it is not necessary to consciously assume a strategic attitude. These are situations in which communication simply flows and generates balances functional to the treatment, which facilitate doctor's work. Other times, however, the relationship with family members is critical, and care may be affected. In these cases, both patient's well-being and that of the healthcare worker are at risk. This happens, for example, with the parents of children with genetic disease, with whom communication is 
more difficult. Indeed, they are discouraged and question the role and the therapeutic "power" of those who cover it. The pediatrician, in these cases, will be strategic if he is able to behave not only as an expert clinician, but also as a process expert. The latter knows how to pick up signals, even the weak ones, and uses them to promote the therapeutic relationship, to generate behaviors in families that are tuned to the achievement of the clinical goal.

\section{Conclusions}

The neonatologist/pediatrician is often the first to observe complex syndromic pictures, not always identified in the prenatal period. He must be aware of all aspects around the genetic diseases, including communication, bioethics, and law [17-26] in view of a multidisciplinary care of the affected newborns and children.

A genetic diagnosis allows the families to feel less fragile, regardless of the benefit that it may have on the clinical management. Next generation sequencing techniques (NGS, which include panel sequencing and whole exome/genome sequencing, WES/WGS) allowed to provide early genetic counseling [27, 28]. When promptly obtained, they may support and guide clinicians to the most appropriate clinical management and communicative approach, avoiding futile and/or disproportionate treatments [29], as well as further unnecessary separations between children and their parents [30].

This consensus provides neonatologists and pediatricians with practical recommendations around the first communication of a genetic disease/malformation syndrome diagnosis. The indications reported may be a useful tool to make easier the informative process, and to implement the best practices in the relationship with families. Communication must not be a marginal or secondary clinical activity. By converse, it requires a careful attention of operators, also considering its clinical and socioeconomic implications on the short and long term. Indeed, a better doctor-patient/family interaction may improve several health outcomes of the child and his family. In addition, it may also reduce the legal disputes with parents and the phenomenon of defensive medicine.

\section{Abbreviations}

$\mathrm{CGH}$ :

comparative genomic hybridization

NGS:

next generation sequencing

NICU:

neonatal intensive care unit 
USA:

United States of America

WES:

whole exome sequencing

WGS:

whole genome sequencing

\section{Declarations}

\section{Ethics approval and consent to participate}

Written informed consent was obtained from both parents at admission of their newborn. The study was approved by the Mother and Child Department of the University of Palermo (Palermo, Italy). All procedures performed in this report were in accordance with the ethical standards of the institutional and national research committee, and with the 1964 Helsinki declaration and its later amendments, or comparable ethical standards.

\section{Consent for publication}

Not applicable.

\section{Availability of data and materials}

The datasets used and analyzed during the current study are available from the corresponding author on reasonable request.

\section{Competing interests}

The authors declare that they have no competing interests.

\section{Funding}

No funding was granted for this research.

\section{Authors' contributions}

GS reviewed the literature and drafted the manuscript. LM coordinated the Consensus, participated in the drafting of the Consensus and to the preparation of the manuscript. AC, MG, Al, ML, DV, AC, SF, TF, FM, LAR, CR, AS, AV and GZ participated in the organization of the Consensus, reviewed the literature and contributed to the preparation of the manuscript. GC designed, coordinated and supervised the Consensus, critically revised the manuscript and gave final approval of the version to be submitted. 


\section{Author details}

${ }^{3}$ University Neonatology Unit, AOU Città della Salute e della Scienza, Turin, Italy.

${ }^{4}$ Unit of Prenatal and Preimplantation Diagnosis, Thalassaemic Hospital, AO Brotzu, Cagliari, Italy

${ }^{5}$ Unit of Obstetrics and Gynecology, Prenatal Diagnosis and Fetal Therapy "U. Nicolini", Buzzi Hospital, ASST FBF Sacco, Milan, Italy

${ }^{6}$ Unit of General Pediatrics, Emergency and Acceptance Department, Bambino Gesù Pediatric Hospital, Rome, Italy

${ }^{7}$ Coordinator of the Italian Association of Down People

${ }^{8}$ President of the Italian National Association of Volunteers Cornelia de Lange

${ }^{9}$ President of the Italian Society of Obstetric and Gynecological Ultrasound and Biophysical Methodologies

${ }^{10}$ President of the Italian Society of Neonatology

${ }^{11}$ President of the Italian Society of Perinatal Medicine

${ }^{12}$ Coordinator of the Clinical Genetics Study Group of the Italian Society of Human Genetics

${ }^{13}$ President of Italian Federation of Rare Diseases and of Williams Syndrome People Association

${ }^{14}$ President of the Italian Society of Pediatrics

${ }^{15}$ President of the Italian Society of Pediatric Genetic Diseases and Congenital Disabilities

\section{Acknowledgements}

We wish to thank the Scientific Societies and their Study Groups as well as the Parents' Associations for their support and cooperation in all phases of the work. We are foremost grateful to all children and their families, without which our work would not have its sense.

\section{References}

1. Petrikin JE, Willig LK, Smith LD, Kingsmore SF. Rapid whole genome sequencing and precision neonatology. Semin Perinatol. 2015;39(8):623-31.

2. Dolk H, Loane M, Garne E. The prevalence of congenital anomalies in Europe. Adv Exp Med Biol. 2010;686:349-64. 
3. Rubanovich CK, Cheung C, Torkamani A, Bloss CS. Physician communication of genomic results in a diagnostic odyssey case series. Pediatrics. 2019;143(Suppl 1):S44-S53.

\section{Smith AM, O'Rahelly M, Flanagan O. Disclosing the diagnosis of Down Syndrome: the experience of 50 Irish parents. Arch Dis Child. 2019;104(8):820-821.}

5. A consensus conference report on defining the eligibility criteria for pediatric palliative care in Italy. Jankovic M, De Zen L, Pellegatta F, Lazzarin P, Bertolotti M, Manfredini L, Aprea A, Memo L, Del Vecchio A, Agostiniani R, Benini F. Ital J Pediatr. 2019;45(1):89.

6. Consensus on Pediatric Pain in the Emergency Room: the COPPER project, issued by 17 Italian scientific societies. Benini F, Corsini I, Castagno E, Silvagni D, Lucarelli A, Giacomelli L, Amigoni A, Ancora G, Astuto M, Borrometi F, Casilli RM, Chiappini E, Cutrera R, De Matteis A, di Mauro G, Musolino A, Fabbri A, Ferrero F, Fornaro M, Gangemi M, Lago P, Macrì F, Manfredini L, Memo L, Minicucci A, Petralia P, Pinelli N, Antonucci R, Tajè S, Tizi E, Venturelli L, Zampogna S, Urbino AF. Ital J Pediatr. 2020;46(1):101.

7. Measuring quality of pediatric care: where we've been and where we're going. Schuster MA. Pediatrics. 2015;135(4):748-51.

8. Ekberg S, Bradford N, Herbert A, Danby S, Yates P. Healthcare users' experiences of communicating with healthcare professionals about children who have life-limiting conditions: a qualitative systematic review protocol. JBI Database System Rev Implement Rep. 2015;13(11):33-42.

9. Butler AE, Copnell B, Hall H. "Some were certainly better than others" - Bereaved parents' judgements of healthcare providers in the paediatric intensive care unit: a grounded theory study. Intens Crit Care Nurs. 2018;45:18-24.

10. Butler AE, Hall H, Copnell B. Becoming a team: the nature of the parent-healthcare provider relationship when a child is dying in the pediatric intensive care unit. J Pediatr Nurs. 2018;40:e26-32.

11. Memo L, Basile E, Ferrarini A, Saia OS, Selicorni A. Communication of diagnosis: pain and grief in the experience of parents of children with a congenital malformation. In: Buonocore G, Bellieni CV (eds), Neonatal pain. Suffering, pain and risk. Springer 2008. Chapter 18. pp 157-160.

12. Sanfilippo JS. Ambiguous genitalia - disorders of sexual differentiation. J Pediatr Adolesc Gynecol. $2011 ; 24(5): 234$.

13. Hughes IA. Disorder of sex development: a new definition and classification. Best Practice Res Clin Endocrinol Metab. 2008;22:119-34.

14. Secci EM, Duò C. Introduzione alla comunicazione strategica nelle professioni sanitarie. ebookecm.it. Collana ebookecm. Ebook per l'educazione continua in medicina. 2018. pp 11-18, 43-48.

15. Mastroiacovo P, Memo L. Raccomandazioni per la comunicazione della diagnosi di malattia genetica complessa e/o disabilità congenita. Prospettive in Pediatria. 2007;37:81-88.

16. Del Giudice E, Langer A, Mastroiacovo P, Quadrino S, Seganti G. Raccomandazioni per la comunicazione della diagnosi di malattia genetica complessa e/o disabilità congenita. In: Orientamenti per famiglie e operatori di bambini con sindrome di Down da 0 a 6 anni. La comunicazione della diagnosi e i controlli di salute. Edizioni Junior 2009, Bergamo. pp 9-20. 
17. R. Lala - G. Fenocchio - A. Musso. Etica e malattie rare. Riflessioni su casi clinici. Nuova Elio Editrice, Torino 2005, pp. 5-6.

\section{Comitato Nazionale per la Bioetica. Gestione degli “incidental findings" nelle indagini genomiche con le nuove piattaforme tecnologiche. 17 Marzo 2016.}

19. Burke K, Muscara F, McCarthy M, Dimovski A, Hearps S, Anderson V, Walser R. Adapting Acceptance and Commitment Therapy for Parents of Children with Life-Threatening IIIness: Pilot Study. Fam Syst Health. 2014 Mar;32(1):122-7.

20. Palazzani L. Dal caso alla scelta. La conoscenza genetica tra nuovi diritti e doveri. In: Gen-ius: la consulenza tra genetica e diritto. Quaderni della Libera Università “Maria SS. Assunta” LUMSA. A cura di L. Palazzani. Edizioni Studium 2011, Roma. pp 25.

21. Clarke AJ, Wallgren-Pettersson C. Ethics in genetic counselling. J Community Genet. 2019; 10(1): 333.

22. Piro E, Schierz IAM, Antona V, Pappalardo MP, Giuffrè M, Serra G, Corsello G. Neonatal hyperinsulinemic hypoglycemia: case report of kabuki syndrome due to a novel KMT2D splicing-site mutation. Ital J Pediatr. 2020;46(1):136.

23. Serra G, Antona V, Corsello G, Zara F, Piro E, Falsaperla R. NF1 microdeletion syndrome: case report of two new patients. Ital J Pediatr. 2019;45(1):138.

24. Corsello G, Antona V, Serra G, Zara F, Giambrone C, Lagalla L, Piccione M, Piro E. Clinical and Molecular Characterization of 112 Single-Center Patients With Neurofibromatosis Type 1. Ital J Pediatr. 2018;44(1):45.

25. Novel LRPPRC compound heterozygous mutation in a child with early-onset Leigh syndrome FrenchCanadian type: case report of an Italian patient. Piro E, Serra G, Antona V, Giuffrè M, Giorgio E, Sirchia F, Schierz IAM, Brusco A, Corsello G. Ital J Pediatr. 2020;46(1):140.

26. Infant developmental profile of Crisponi syndrome due to compound heterozygosity for CRLF1 deletion. Schierz IAM, Serra G, Antona V, Persico I, Corsello G, Piro E. Clin Dysmorphol. 2020;29(3):141-143.

27. Hayeems RZ, Boycott KM. Genome-wide sequencing technologies: a primer for paediatricians. Paediatr Child Health. 2018;23(3):191-197.

28. Borghesi A, Mencarelli MA, Memo L, Ferrero GB, Bartuli A, Genuardi M, Stronati M, Villani A, Renieri A, Corsello G; their respective Scientific Societies. Intersociety policy statement on the use of wholeexome sequencing in the critically ill newborn infant. Ital J Pediatr. 2017;43(1):100.

29. De Curtis M, Palazzani L. Mozione del Comitato Nazionale per la Bioetica. Problematiche bioetiche della società. Riflessioni bioetiche su accanimento clinico o ostinazione irragionevole dei trattamenti sui bambini piccoli con limitate aspettative di vita. 30 Gennaio 2020.

30. Serra G, Corsello G, Antona V, D'Alessandro MM, Cassata N, Cimador M, Giuffrè M, Schierz IAM, Piro E. Autosomal recessive polycystic kidney disease: case report of a newborn with rare PKHD1 mutation, rapid renal enlargement and early fatal outcome. Ital J Pediatr. 2020;46(1):154. 


\section{Tables}

Table 1. Indications for the neonatologist and the pediatrician to make easier the communication of a genetic disease and/or malformation syndrome diagnosis, and to implement the best practices in the relationship with families $[15,16]$. 
When

- The first interview with the parents/family members should be carried out at the time of the clinical diagnosis (postponing the communication until the karyotype is available, for example in the case of Down syndrome, is considered unprofessional and intolerable by the family).

- In cases of long-lasting diagnostic pathways (for example diagnosis of genetic and/or genomic diseases made by array-CGH/NGS techniques), it is necessary to share with parents the different moments and results obtained during the diagnostic process

- In cases where the diagnosis is not defined, it is however possible to make a functional diagnosis, to which refer to for care program and follow-up planning.

Who

- Clinical geneticist and/or neonatologist or other specialist who has direct knowledge of the newborn, with competence on the disease object of the diagnosis and, if possible, the responsibility of care.

- Genetic diseases are frequently burdened by the presence of malformations affecting multiple organs and systems and require multi-specialty/multiprofessional management. Therefore, other specialists (e.g. pediatric surgeon) and health professionals (e.g. physiotherapist) should be present or available.

- For those born to foreign parents the presence of the cultural mediator is useful.

With whom

- The first meeting to communicate the diagnosis should be carried out with both parents (avoiding the presence of other figures not directly involved in care).

- If the mother is not in good clinical conditions, the first communication may be made with the father (with whom times and methods to inform the mother should be agreed).

- The interview must be carried out in front of the newborn. His presence allows parents to be guided towards his physiological characteristics, skills, and potential.

- In subsequent meetings, the involvement of family pediatrician, other specialists/health professionals, other family members/trusted persons, representative of the reference Association (if available) may be agreed. A multidisciplinary management (gynecologist, obstetrician, neonatologist, surgeon, psychologist ...), may guarantee to families a global, integrated and continuous care, and reduce the risk of disorientation or sense of abandonment.

Where

A private environment must be identified:

free from possible interruptions (by telephone, other colleagues, etc ...);

available exclusively to parents at the end of the interview.

How

- In a proactive way, with empathy and respect.

- Balance honesty and frankness (it is better a sincere "I don't know" than incorrect or inaccurate indications, with negative repercussions on the whole life of the child and the family) with the need of parents to maintain hope for the survival of their baby.

- Speak simply and clearly, using common language and minimizing jargon.

- Avoid the attitude of over-describing the clinical aspects.

- Refer to the child by name. 
- Ensure continuous and direct eye contact.

- Arrange distances in the range of 50-100 cm, i.e. between "personal" and "social", placing the chairs side by side and not in front (the interposition of the desk may be perceived as an obstacle to communication).

- Accept the experience of family members and their vision of things, without directly contesting them.

- Provide practical and emotional support to the process of remodeling parents' role.

- Suspend critical judgment, interpretations and "thought readings" during the interview.

- Provide first the positive aspects of a news, and then introduce the negative ones.

- Use the first plural person (we) instead of the first or second singular one.

- Avoid impersonal expressions, and directly refer to the experience of parents.

- Assess parents' knowledge, their cultural background, and ethical visions, as well as the ability to understand what is explained to them.

- Facilitate questions and requests from parents with opening speeches.

How long

- First meeting without time limits, however avoiding overflowing interviews that lose effectiveness and increase the risk of misunderstandings.

- Provide more meetings, as needed, with different methods and professionals.

- In any case, dedicate all the time you need to communication. The "psychic time" of parents, necessary for accepting a child unlike from what they imagined until that moment, is often different than that of the medical intervention. Recognizing this time and being generous with one's own have, then, a therapeutic as well as an ethical value.

What

- Provide updated information on the main characteristics of the newborn's disease, reporting only the most frequent complications, without listing the rarest or most unlikely ones (which indicate theoretical knowledge, but which do not give any benefit to the family).

- Explain genetic and/or genomic diagnostic procedures, documenting the clinical indications.

- Perform a physical examination of the newborn together with the parents, underlining his physiological features.

- Formulate an individualized and realistic prognosis (not theoretical and applicable in a generic way to other patients with the same disease), and perform a reproductive counseling.

- Describe the care program and provide information on follow-up, reference center and local services.

With which supports/helps
- Informatic and/or written material (brochures, information booklets also relating to the presentation of the reference Association), web guided navigation.

- Parents/families' associations, institutions. 